\title{
William A. Tooman
}

\section{Gog of Magog}

Reuse of Scripture and Compositional Technique in Ezekiel 38-39

[Gog aus Magog. Zur Wiederverwendung älterer heiliger Texte und zur Kompositionstechnik in Hesekiel 38-39.]

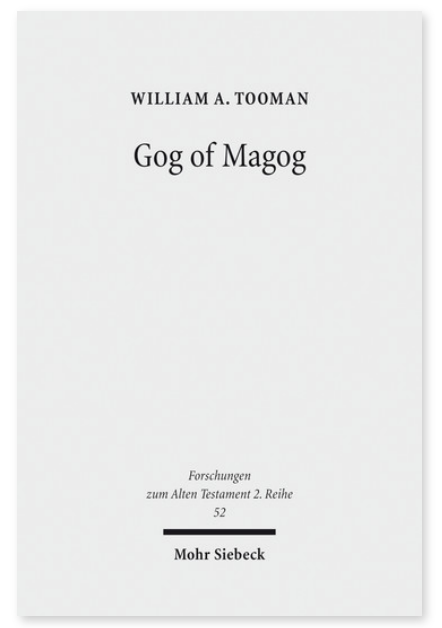

2011. XI, 343 Seiten. FAT II 52

ISBN 978-3-16-151752-5

DOI 10.1628/978-3-16-151752-5

eBook PDF $104,00 €$

ISBN 978-3-16-150857-8

fadengeheftete Broschur 104,00€
Veröffentlicht auf Englisch.

Die Art und Weise, wie ältere Texte in den Gog-Orakeln (Hesekiel 38-39) wiederverwendet werden, ist der Schlüssel zu deren Zweck und Bedeutung. Die fortlaufenden Anspielungen weisen auf mehr hin, als nur auf einen Verfasser mit einer Vorliebe für Idiome aus heiligen Texten. Vielmehr zeigt sich hier eine wohl durchdachte und disziplinierte Verweistechnik auf ausgewählte Texte zu ausgewählten Themen. William Tooman macht in seiner Studie deutlich, dass die Beschäftigung mit diesen Anspielungen unerlässlich für ein Verständnis der Rolle der Kapitel innerhalb des ganzen Buches, seines Aufbaus und seiner Stellung in der antiken jüdischen Literatur ist. Er untersucht die Methoden, die Wirkung und die Motivation für die Wiederverwendung älterer heiliger Texte innerhalb der Gog-Orakel und zeigt, dass diese Kapitel eine eigene Dichtung sind, die als Ergänzung zum Buch Hesekiel geschaffen wurde, um so die Botschaft des Buches zu ergänzen und es anderen prophetischen Schriften anzupassen.

William A. Tooman Born 1969; 2006 PhD; 2006-09 Assistant Professor of Religious Studies and 2009 Associate Professor of Religious Studies, Edgewood College; 2009-13 Lecturer in Hebrew Bible, University of St Andrews; since 2013 Senior Lecturer in Hebrew Bible and Divinity Director of Research, University of St Andrews.

\author{
Jetzt bestellen: \\ https://mohrsiebeck.com/buch/gog-of-magog-9783161517525?no_cache=1 \\ order@mohrsiebeck.com \\ Telefon: +49 (0)7071-923-17 \\ Telefax: $+49(0) 7071-51104$
}

